\title{
Sınıf 3 maloklüzyonlarda hızlı üst çene genişletmesi ile birlikte yüz maskesi uygulamasının ve takiben yapılan sabit ortodontik tedavinin etkileri
}

\author{
Erdal Bozkaya iD, ${ }^{*}$ Arife Nihan Toğral, Sema Yüksel \\ Ortodonti Anabilim Dalı, Diş Hekimliği Fakültesi, \\ Gazi Üniversitesi, Ankara, Türkiye
}

\section{Özet}

AmAÇ: Bu çalışmada üst çene gelişim yetersizliği bulunan Sınıf 3 maloklüzyonlarda hızlı üst çene genişletilmesi ve yüz maskesi ile sonrasında yapılan sabit ortodontik tedavinin etkilerinin değerlendirilmesi amaçlanmıştır.

GEREÇ VE YöNTEM: Bu çalıșmada, hızlı üst çene genişletmesiyle birlikte yüz maskesi uygulanmış ve sonrasında sabit ortodontik tedavi görmüş 20 bireyin (11 kadın, 9 erkek, kronolojik yaş medyan değeri 11.29 yıl) arşiv materyalleri kullanıldı. Çalışmaya dâhil edilen bireylerin tedavi öncesi (TO), hızlı üst çene genişletilmesi ile birlikte yüz maskesi uygulaması sonrası (T1) ve sabit tedavi sonrasında (T2) alınan lateral sefalometrik radyografiler üzerinde değerlendirmeler yapıldı. Elde edilen verilerin istatistiksel analizinde Friedman testi ile Bonferroni düzeltmeli Wilcoxon testi kullanıldı. Bulguların yorumlanması sırasında $p<0.05$ istatistiksel olarak anlamlı kabul edildi.

BULGULAR: Yüz maskesi uygulama süresi 13 ay (T1-T0), sabit ortodontik tedavi 2 yıl 1 ay (T2-T1), toplam tedavi süresi ise 3 yıl 2 aydı (T2-T0). SNA açısındaki ve Co-A mesafesindeki artış, T1-T0 ( $p<0.001)$ ve T2-T0 (SNA: $p<0.001$, Co-A: $p<0.01)$ dönemlerinde anlamlı bulundu. SNB açısı T1-TO döneminde anlamlı azalma ( $p<0.01)$; Co-Gn uzunluğu ise her üç dönemde de anlamlı artış gösterdi (T1-T0 ve T2-T1: p<0.05, T2-T0: $p<0.001)$. SN/GoGn açısı T1-T0 $(p<0.05)$ ve T2-T0 ( $p<0.001)$ dönemlerinde anlamlı düzeyde arttı. ANB açısında T1-T0 ve T2-T0 dönemlerinde anlamlı artış elde edildi $(p<0.001)$

Sonuç: İskeletsel Sınıf 3 maloklüzyonların tedavisinde, hızlı üst çene genişletmesi ve yüz maskesinin birlikte uygulanması etkili bir yöntemdir. Sabit ortodontik tedavi sonrası üst ve alt çenenin uyumlu bir biçimde büyümeye devam etmesiyle kalıcı sonuçlar elde edilmiştir.

Makale gönderiliş tarihi: 10 Eylül 2020; Yayına kabul tarihi: 5 Ocak 2021 * Iletișim: Dr. Erdal Bozkaya, Gazi Üniversitesi Diş Hekimliği Fakültesi, Ortodonti Anabilim Dalı, 06510, Emek, Ankara, Türkiye;

E-posta: erdalbozkaya@gmail.com
Anahtar Kelimeler: Angle Sınıf 3; maloklüzyon; ortodontik gereçler

KaynaK GöStermek İçin: Bozkaya E, Toğral AN, Yüksel S. Sınıf 3 maloklüzyonlarda hızlı üst çene genişletmesi ile birlikte yüz maskesi uygulamasının ve takiben yapılan sabit ortodontik tedavinin etkileri. Acta Odontol Turc 2021;38(2):49-55

ЕрітӧR: Emine Kaygısız, Gazi Üniversitesi, Ankara, Türkiye

YAYıN HAKKI: @ 2021 Bozkaya ve ark. Bu eserin yayın hakkı Creative Commons Attribution License ile ruhsatlandırılmıştır. Sınırsız kullanım, dağıtım ve her türlü ortamda çoğaltım, yazarlar ve kaynağın belirtilmesi kaydıyla serbesttir.

Finansal Destek: Bulunmamaktadır.

ÇıKAR ÇATIŞMASI: Bulunmamaktadır.

[Abstract in English is at the end of the manuscript]

\section{Giriş}

İskeletsel Sınıf 3 maloklüzyonlar, toplumda az görülmesine rağmen hastaların hem estetik hem de fonksiyon açısından en fazla rahatsızılık duyduğu ortodontik problemlerden biri olup, tedavileri için diğer maloklüzyonlara göre daha erken dönemlerde ortodontistlere yönlendirilmektedirler. ${ }^{1} \mathrm{Bu}$ maloklüzyonlar hem tedavilerinin zahmetli olması hem de nüks ihtimaline karşı uzun süreli takip intiyacı nedeniyle tedavisi zor düzensizlikler olarak kabul edilmektedirler. Günümüzde iskeletsel Sınıf 3 maloklüzyonların büyüme ve gelişim döneminde tedavi edilmesinin bireyin fiziksel görünüşündeki iyileşmeye bağlı olarak psikolojik gelişimini olumlu yönde etkilediği, ayrıca bu döneminde müdahale edilmeyen olguların tedavilerinin ileriki dönemde zorlaşabileceği bildirilmektedir. ${ }^{2-4}$

İskeletsel Sınıf 3 maloklüzyonların oluşumunda üst çenenin gelişim yetersizliği \%20-37 oranında tek başına etkili olup, ${ }^{5,6}$ bu tip maloklüzyonların büyüme ve gelişim dönemindeki tedavilerinde en sık kullanılan ağız dışı aygıtlar ortopedik yüz maskeleridir. Yüz maskesi aracılığıyla üst çeneye uygulanan kuvvet ile üst çeneye komşu sütürlerdeki büyüme uyarılarak üst çenenin ileri yön gelişiminin arttırılması hedeflenmektedir. ${ }^{7}$ Literatürde hızlı üst çene genişletilmesinin üst çenenin çevre sütürlerle olan bağlantısını zayıflattığı, bu sütürlerde 
hücresel aktiviteyi arttırdığı, bu sayede yüz maskesi ile birlikte kullanılmasının üst çenenin ileri yön büyümesine katkı sağladığı bildirilmektedir. ${ }^{8-11}$

İskeletsel Sınıf 3 maloklüzyonların tedavilerinde yüz maskesi ve hızlı üst çene genişletilmesinin birlikte uygulanmasının, iskeletsel ve dişsel yapıda meydana getirdiği değişiklikler pek çok kez araştırılmış ve sonuçları yayınlanmıştır., ${ }^{2,8-13}$ Ancak, bu çalışmaların sonuçları sadece yüz maskesi ve hızlı üst çene genişletilmesinin aktif uygulama dönemine ait olduğu gözlenmektedir. Büyüme ve gelişimin erken döneminde yapılan bu tedavilerin sonuçlarının olumlu olduğu iyi bilinse de ortopedik düzeltme sonrasında baş ve yüz çevresindeki iskeletsel yapılarda uzun dönemde meydana gelen değişimleri inceleyen çalışmalar farklı görüşler rapor etmektedirler. Westwood ve ark. ${ }^{14}$ hızlı üst çene genişletilmesi ile birlikte uygulanan yüz maskesinin üst çenenin ileri yön büyümesine olumlu katkı sağladığını, daha sonra yapılan sabit ortodontik tedavi ile bu değişimlerin stabil kaldığını ancak bu dönemde kraniofasial yapılardaki büyümenin iskeletsel Sınıf 3 maloklüzyonun karakteristiklerini gösterdiğini bildirmişlerdir. Pangrazio-Kulbersh ve ark. ${ }^{15}$ ise aktif yüz maskesi tedavisi sonrası yapılan sabit ortodontik tedavi sırasında da üst çenedeki büyümenin, tedavi edilmemiş kontrol gruplarına göre daha fazla olduğunu rapor etmişlerdir. Chen ve ark.$^{16}$ maksiller protraksiyon sonrası uzun dönem takipli çalışmalarında, üst çenede hafif retrüzyon ve alt çenede ciddi ileri yön büyümenin stabiliteyi olumsuz yönde etkilediğini bildirmişlerdir. Pavoni ve arkadaşlarına ${ }^{17}$ göre Sınıf 3 maloklüzyonların tedavisi sonrası uzun dönemde stabil kalan profil değerlerinin aslında yüz maskesi ve hızlı üst çene genişletmesi fazında elde edilen değişimin bir sonucu olduğunu bildirmişlerdir. Kaygısız ve Yüksel, ${ }^{18}$ yüz maskesi ile başarılı bir şekilde tedavi edilmiş Sınıf 3 maloklüzyona sahip bireylerin uzun dönem takiplerinde üst çenedeki büyümenin aktif protraksiyon tedavisi dönemine göre daha az olmasının, buna karşılık alt çenenin büyümeye devam etmesinin nüksün bir göstergesi olabileceğini bildirmişlerdir.

$\mathrm{Bu}$ çalışmada üst çenenin gelişim yetersizliğine bağlı iskeletsel Sınıf 3 maloklüzyona sahip bireylere büyüme ve gelişim dönemlerinde uygulanan hızlı üst çene genişletilmesi ile birlikte ortopedik yüz maskesi ve ortopedik uygulamadan sonra yapılan sabit ortodontik tedavinin iskeletsel ve dişsel yapılarda oluşturduğu değişikliklerin değerlendirilmesi amaçlanmıştır. Çalışmamız, hızlı üst çene genişletmesi ve yüz maskesi uygulamasının iskeletsel Sınıf 3 maloklüzyona sahip bireylerin kraniyofasiyal yapılarında meydana getirdiği değişimlerin sabit ortodontik tedavi süresince korunduğu ve bu dönemin sonunda nüks gözlenmediği hipotezi üzerine kurulmuştur.

\section{Gereç Ve Yöntem}

Bu çalışma Gazi Üniversitesi Diş Hekimliği Fakültesi Ortodonti Anabilim Dalında hızlı üst çene genişletmesiyle birlikte yüz maskesi uygulanmış ve sonrasında sa- bit ortodontik tedavi görmüş bireylerin arşivde bulunan kayıtları kullanılarak yürütüldü. Çalışmanın etik onayı Gazi Üniversitesi Etik Komisyonundan alındı (Onay Numarası: 2020-313).

Çalışmanın örneklem büyüklüğü hesaplanırken G*Power 3.1.3 yazılımı (Franz Faul, Kiel Üniversitesi, Almanya) kullanılmış olup daha önce yapılmış benzer bir çalışmadaki ${ }^{14}$ ortalama ve standart sapmalar göz önünde bulundurularak $\alpha=0.05, \beta=0.20$ ve etki büyüklüğü 0.8 kabul edildiğinde 20 bireyin çalışmaya dâhil edilmesi gerektiği belirlendi.

Çalışmaya şu ölçütlere uyan bireyler dâhil edildi: (1) Üst çene gelişim yetersizliğine bağlı iskeletsel Sınıf 3 $\left(\mathrm{ANB}<0^{\circ}\right)$ bireyler; (2) Dişsel Angle Sınıf III maloklüzyona sahip bireyler; (3) Dik yönde normal büyüme yönüne

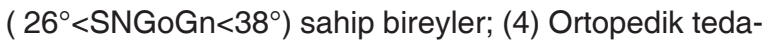
vilerinde arka grup dişlerin yüzeyini kaplayan hızı üst çene genişletme apareyinden destek alınarak yüz maskesi uygulanmış bireyler; (5) Ortopedik tedavi sonrası diş çekimsiz sabit ortodontik tedavi görmüş bireyler; (6) Herhangi bir gelişimsel sendromu bulunmayan bireyler.

Çalışmaya şu ölçütlere uyan bireyler ise dâhil edilmedi: (1) Arşiv kayıt bilgilerine göre tedavilerini yarıda bırakan bireyler (2) Ortopedik tedavilerinde farklı tipte hızlı üst çene genişletme apareyi veya yüz maskesi uygulanmış bireyler; (3) Ortopedik tedavi sonrası diş çekimli sabit ortodontik tedavi görmüş bireyler.

Örneklem büyüklüğü hesaplamaları ve dâhil edilme ölçütleri göz önünde bulundurularak çalışmaya 20 bireyin (11 kadın, 9 erkek, ortalama kronolojik yaş: $11.2 \pm$ 1.18 yıl) arşiv kayıtları dâhil edildi.

Çalışmaya dâhil edilen bireylerin arşiv kayıtlarına göre ortopedik tedavilerinde Petit tipi yüz maskesi kullanıldı. Ağız içi aygıt olarak ise üst çenede arka grup dişleri kaplayan akrilik düz yüzeyli hızlı üst çene genişletme apareyi kullanıldı. Tüm hastalarda ağız içi aygıtın üst kanin ve birinci premolar dişler arasında bulunan çift tarafı $F$ kroşelerinden yüz maskesine oklüzal düzlemle

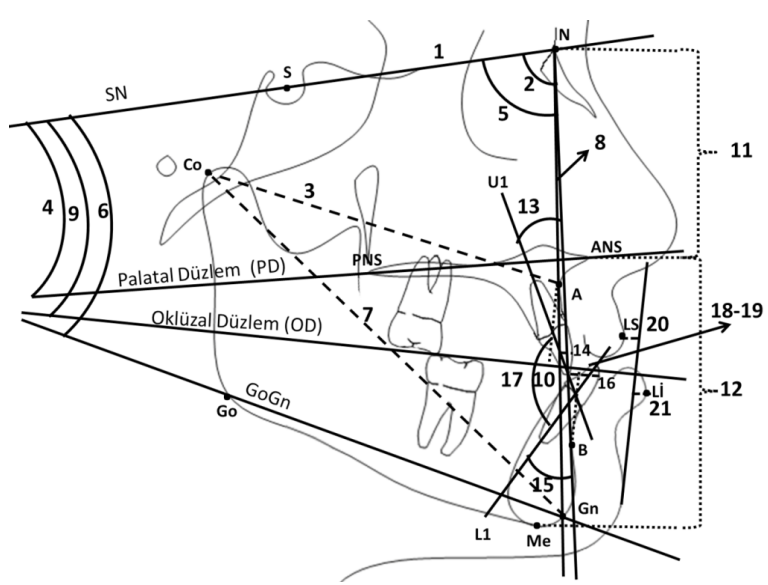

Şekil 1. Lateral sefalometrik filmler üzerinde yapılan ölçümler: 1: S-N, 2: SNA, 3: Co-A, 4: SN/PD, 5: SNB, 6: SN/GoGn, 7: Co-Gn, 8: ANB, 9: SN/OD, 10: Wits, 11: N-ANS, 12: ANS-Me, 13: U1/NA, 14: 1-NA, 15: L1/NB, 16: 1-NB, 17: U1/L1, 18: Overjet, 19: Overbite, 20: LS-S, 21: Li-S 
Tablo 1. Çalışmaya dâhil edilen bireylerin tüm dönemlere ait tanımlayıcı istatistikleri ve gruplararası farkların incelenmesi

\begin{tabular}{|c|c|c|c|c|c|c|c|c|c|c|}
\hline & \multicolumn{2}{|r|}{ TO } & \multicolumn{2}{|r|}{ T1 } & \multicolumn{2}{|r|}{ T2 } & \multirow{2}{*}{$\begin{array}{c}\text { Friedman } \\
\text { test }\end{array}$} & \multicolumn{3}{|c|}{$\mathrm{P}$} \\
\hline & Ort $\pm S S$ & Med (Min-Maks) & Ort $\pm S S$ & Med (Min-Maks) & Ort $\pm S S$ & Med (Min-Maks) & & T0-T1 & T1-T2 & T0-T2 \\
\hline Yaş (yıl) & $11.16 \pm 1.18$ & $11.29(9-13.5)$ & $12.29 \pm 1.18$ & $12.38(10.33-14.5)$ & $14.32 \pm 1.53$ & $14.42(10.75-16.83)$ & $<0.001$ & 0.005 & 0.005 & $<0.001$ \\
\hline S-N (mm) & $71.1 \pm 3.42$ & $70.5(65-77)$ & $72.58 \pm 3.26$ & $73(67-78)$ & $73.93 \pm 2.98$ & $74(68-79)$ & $<0.001$ & 0.002 & 0.119 & $<0.001$ \\
\hline SNA $\left(^{\circ}\right)$ & $77.63 \pm 3.35$ & $78.5(70-85)$ & $80.13 \pm 3.56$ & $80(73-87.5)$ & $80.6 \pm 3.62$ & $80(74-88)$ & $<0.001$ & $<0.001$ & 0.912 & $<0.001$ \\
\hline Co-A (mm) & $83.83 \pm 4.95$ & 82.5 (78-95) & $86.93 \pm 5.48$ & 85.5 (81-99) & $88.88 \pm 5.53$ & 88 (82-99) & $<0.001$ & 0.002 & 0.066 & $<0.001$ \\
\hline SN/PD $\left({ }^{\circ}\right)$ & $9.08 \pm 2.82$ & $9.25(5-15)$ & $8.55 \pm 3.06$ & $8.5(3-15)$ & $9.23 \pm 2.98$ & $9(3-15)$ & 0.083 & - & - & - \\
\hline SNB $\left({ }^{\circ}\right)$ & $79.80 \pm 3.08$ & $80(75-88)$ & $78.45 \pm 2.9$ & $78(73-85.5)$ & $78.7 \pm 3.4$ & $78(73-87)$ & 0.001 & 0.003 & 0.707 & 0.098 \\
\hline SN/GoGn $\left({ }^{\circ}\right)$ & $31.9 \pm 3.58$ & $30.5(26-38)$ & $33.55 \pm 3.34$ & $33.5(28.5-41)$ & $34.1 \pm 3.31$ & $34(29-42)$ & $<0.001$ & 0.022 & 0.246 & $<0.001$ \\
\hline Co-Gn (mm) & $114.55 \pm 5.91$ & $113(105-128)$ & $116.33 \pm 6.24$ & $115.5(105-130)$ & $119.78 \pm 8.56$ & $119(107-146)$ & $<0.001$ & 0.043 & 0.010 & $<0.000$ \\
\hline ANB $\left({ }^{\circ}\right)$ & $-2.08 \pm 1.54$ & $-1.75(-5-0)$ & $1.73 \pm 1.45$ & $1.75(-1-5)$ & $1.7 \pm 1.49$ & $1(0-5)$ & $<0.001$ & $<0.001$ & 0.933 & $<0.001$ \\
\hline SN/OD $\left({ }^{\circ}\right)$ & $17.53 \pm 2.56$ & $18(12-24)$ & $16.9 \pm 3.01$ & $16.75(12-22)$ & $17.43 \pm 2.98$ & $17(13-23)$ & 0.164 & - & - & - \\
\hline Wits (mm) & $-6.45 \pm 2.33$ & $-6.5(-10--2)$ & $-2.3 \pm 3.06$ & $-3(-8-4)$ & $-1.65 \pm 3.05$ & $-1(-8-3)$ & $<0.001$ & $<0.001$ & 1.000 & $<0.001$ \\
\hline N-ANS (mm) & $53.55 \pm 3.58$ & $53.5(48-61)$ & $54.93 \pm 3.94$ & $55.5(49-63)$ & $56.15 \pm 3.62$ & $56.5(50-63)$ & $<0.001$ & 0.013 & 0.053 & $<0.001$ \\
\hline ANS-Me (mm) & $63.75 \pm 4.8$ & $64(57-72)$ & $67.9 \pm 5.85$ & $66.5(60-79)$ & $69.5 \pm 6$ & $68.5(59-81)$ & $<0.001$ & 0.005 & 0.081 & $<0.001$ \\
\hline U1/NA $\left({ }^{\circ}\right)$ & $29.25 \pm 18.62$ & $26(18-106)$ & $28.25 \pm 18.77$ & $24.5(16-106)$ & $30.5 \pm 19$ & $26.5(15-109)$ & $0.012^{*}$ & 1.000 & 0.017 & 0.144 \\
\hline 1-NA (mm) & $5.78 \pm 1.91$ & $5(3-10)$ & $5.78 \pm 1.8$ & $6(2-9)$ & $6.38 \pm 2.08$ & $6.5(2-12)$ & 0.062 & - & - & - \\
\hline L1/NB $\left({ }^{\circ}\right)$ & $22 \pm 7.15$ & $22(10-32)$ & $21.23 \pm 6.58$ & $21.5(11-30)$ & $20.25 \pm 6.38$ & $20.5(10-34)$ & 0.523 & - & - & - \\
\hline 1-NB (mm) & $4.63 \pm 2$ & $4(1.5-8)$ & $4.15 \pm 2.2$ & $3(1.5-8)$ & $4.33 \pm 2.21$ & $4(2-10)$ & 0.255 & - & - & - \\
\hline U1/L1 $\left({ }^{\circ}\right)$ & $134.2 \pm 11.08$ & $134.5(118-158)$ & $133.3 \pm 8.49$ & $132(117-147)$ & $129.88 \pm 11.03$ & $130(100-153)$ & 0.006 & 1.000 & 0.022 & 0.017 \\
\hline Overjet (mm) & $-1.45 \pm 1.15$ & $-1.5(-4-0)$ & $2.4 \pm 1.08$ & $2(1-5)$ & $2.15 \pm 0.49$ & $2(2-4)$ & $<0.001$ & $<0.001$ & 1.000 & $<0.001$ \\
\hline Overbite (mm) & $2.18 \pm 2.03$ & $2.75(-1-6)$ & $1.93 \pm 1.05$ & $2(0-4)$ & $2.08 \pm 0.24$ & $2(2-3)$ & 0.707 & - & - & - \\
\hline LS-S (mm) & $-1.2 \pm 2.94$ & $-1(-9-4)$ & $0.6 \pm 1.87$ & $0(-3-4)$ & $0.68 \pm 1.99$ & $1(-3-4)$ & 0.001 & 0.002 & 1.000 & 0.008 \\
\hline Lì-S (mm) & $1.73 \pm 2.97$ & $2(-3-7)$ & $1.08 \pm 2.14$ & $1(-3-5)$ & $0.9 \pm 1.97$ & $1(-2-5)$ & 0.405 & - & - & - \\
\hline
\end{tabular}

Ort: Ortalama, SS: standart sapma, Med: medyan, Min: minimum, Maks: maksimum

yaklaşık $30^{\circ}$ açı yapacak ve tek taraflı $400 \mathrm{~g}$ kuvvet uygulayacak şekilde elastikler uygulandı. Tedavi süresince hastaların yüz maskesini günde 16-18 saat kullandıkları belirlendi. Hızlı üst çene genişletme işlemi günde 1 tur $(0.25 \mathrm{~mm})$ çevrilerek 4-6 hafta arasında sürmüş olup, $2 \mathrm{~mm}$ veya üzerinde pozitif overjet elde edilen bireylerde yüz maskesi uygulaması sonlandırıldı. Bireylerin tamamına ortopedik uygulama sonrasında 18 inç slot genişliğine sahip Roth sistem (Gemini, 3M Unitek, Monrovia Kalifornia, ABD) bant ve braketler ile çekimsiz sabit tedavi uygulandı. Sabit tedavi sırasında molar distalizasyonu, keser protrüzyonu, arklarla genişletme, interproksimal aşındırma gibi yer kazanma yolları kullanılarak Sınıf III ağız içi elastikler uygulandı.

Değerlendirmeler; tedavi öncesi (T0), hızlı üst çene genişletilmesi ile birlikte yüz maskesi uygulaması sonrası (T1) ve sabit tedavi sonrasında (T2) alınan lateral sefalometrik filmler üzerinde yapıldı. Tüm lateral sefalometrik film çakıştırmaları ve ölçümleri aynı kişi (ANT) tarafından elle gerçekleştirildi. Her bir sefalometrik film üzerinde 9 açısal, 12 doğrusal ölçüm yapıldı (Şekil 1).

\section{İstatistiksel analiz}

Verilerin istatistiksel analizi için SPSS 24.0 (IBM Corp., Armonk, NY, USA) paket programı kullanıldı. Değişkenlerin normal dağılım gösterip göstermedikleri Shapiro Wilk testi ile araştırıldıktan sonra 3 farklı zamanda yapılan ölçümlerin analizinde Friedman testi kullanıldı. Anlamlı bulunan verilerin post-hoc karşılaştırılmaları için Bonferroni düzeltmeli Wilcoxon testi yapıldı. Bulguların yorumlanması sırasında $p<0.05$ istatistiksel olarak anlamlı kabul edildi. Tanımlayıcı istatistikler ortalama \pm standart sapma ve medyan (minimum-maksimum) verileri ile gösterildi. Dağılımların parametrik özellik göstermemesi nedeniyle yorumlamalar, medyan değerleri üzerinden yapıldı.

\section{Bulgular}

Çalışmaya ait tanımlayıcı istatistik verileri, yüz maskesi uygulaması sonrası (T1-T0), sabit tedavi sonrası (T2T1) ve toplam tedavi sonrası (T2-T0) değişimler ve bu değişimlerin istatistiksel karşılaştırma sonuçları Tablo 1 'de gösterilmiştir.

Çalışmaya dâhil edilen bireylerin tedavi başı kronolojik yaşı medyan değeri 11.29 yıldı. Yüz maskesi uygulaması 13 ay (T1-T0), sabit ortodontik tedavi ortalama 2 yıl 1 ay (T2-T1), toplam tedavi süresi ise 3 yıl 2 ay (T2-T0) sürdü.

Ön kafa kaidesi uzunluğu (S-N), yüz maskesi uygulaması sonrası $(T 1-T 0)(p<0.01)$ ve toplam sürede (T2-T0) $(p<0.001)$ istatistiksel olarak anlamlı artışlar gösterdi.

Üst çenedeki değişimler incelendiğinde medyan değerlere göre SNA açısında yüz maskesi uygulaması sonunda (T1-T0) $1.5^{\circ}$ istatistiksel olarak anlamlı artış gözlendi ve bu değişim sabit tedavi süresince korundu (T2-T0) $(p<0.001)$. Üst çenenin efektif uzunluğunda (Co-A) yüz maskesi uygulaması sonrası (T1-T0) $3 \mathrm{~mm}$ $(p<0.01)$, toplam tedavi süresi sonunda (T2-T0) ise 5.5 $\mathrm{mm}(\mathrm{p}<0.001)$ anlamlı artış elde edildi.

Alt çenedeki değişimler incelendiğinde, SNB açısında yüz maskesi uygulaması sonunda (T1-T0) $2^{\circ}$ 'lik istatistiksel olarak anlamlı azalma gözlendi $(p<0.01)$. Alt çenenin efektif uzunluğunda (Co-Gn) yüz maskesi uygulaması sonrası (T1-T0) $2.5 \mathrm{~mm}(\mathrm{p}<0.05)$, sabit ortodontik tedavi sonrası (T2-T1) $3.5 \mathrm{~mm}(\mathrm{p}<0.05)$, toplam tedavi süresi sonunda (T2-T0) ise $6 \mathrm{~mm}(p<0.001)$ 
anlamlı artış elde edildi. Alt çene düzlem açısında (SN/ GoGn) yüz maskesi uygulaması sonrası (T1-T0) $3^{\circ}$ $(p<0.05)$, toplam tedavi süresi sonunda (T2-T0) ise $3.5^{\circ}$ $(p<0.001)$ anlamlı artış meydana geldi.

Alt ve üst çenenin birbirine göre konumları incelendiğinde, yüz maskesi uygulaması sonrası (T1-T0) ANB açısında $3.5^{\circ}$, Wits değerinde $3 \mathrm{~mm}$; toplam tedavi süresinde (T2-T0) ise ANB açısında $2.75^{\circ}$, Wits değerinde $5.5 \mathrm{~mm}$ istatistiksel olarak anlamlı artış elde edildi $(p<0.001)$.

Üst ön yüz yüksekliği (N-ANS) yüz maskesi uygulaması sonrası (T1-T0) $2 \mathrm{~mm}(\mathrm{p}<0.05)$ ve toplam sürede de (T2-T0) $3 \mathrm{~mm}$ anlamlı artış gösterdi $(p<0.01)$. Benzer şekilde alt ön yüz yüksekliği (ANS-Me) yüz maskesi uygulaması sonrası (T1-T0) $2.5 \mathrm{~mm}(\mathrm{p}<0.01)$ ve toplam sürede de (T2-T0) $4.5 \mathrm{~mm}(\mathrm{p}<0.001)$ anlamlı artış gösterdi.

Dişsel değişimlere bakıldığında, üst kesici dişlerde sabit tedavi sonrasında görülen (T2-T1) $2^{\circ}$ protrüzyon (U1/NA, $p<0.05$ ) istatistiksel olarak anlamlı bulundu. İnterinsizal açıda (U1/L1) sabit tedavi sonrası (T2-T1) $2^{\circ}$, toplam tedavi süresinde ise (T2-T0) $4.5^{\circ}$ anlamlı azalma meydana geldi $(p<0.05)$. Overjette yüz maskesi uygulaması sonrası ve toplam tedavi süresinde $3.5 \mathrm{~mm}$ anlamlı artış meydana geldi $(\mathrm{p}<0.001)$.

Yumuşak doku değişimleri incelendiğinde üst dudağın Steiner'in S düzlemine olan mesafesinin (LS-S) yüz maskesi uygulaması sonrası $1 \mathrm{~mm}$, toplam tedavi süresinde ise $2 \mathrm{~mm}$ anlamlı artış gösterdiği gözlendi $(p<0.01)$.

\section{TARTIŞMA}

İskeletsel Sınıf 3 maloklüzyonların tedavilerinde ortopedik yüz maskeleri kısa dönemde olumlu sonuçlar vermekle birlikte tedavinin uzun dönem sonuçlarının araştırılması ve anlaşılması başarılı tedavi sonuçları için hem klinisyenler hem de hastalar açısından önemli role sahiptir. Bu maloklüzyonların tedavilerinde uzun dönem başarının sağlanmasının, tedaviden sonraki iskeletsel, kassal ve dişsel adaptasyonlar ile baş ve yüz yapılarının büyümesinin bütünü ile doğrudan ilişkili olduğu bildirilmektedir. ${ }^{14,19}$

Literatürde Sınıf III maloklüzyonların büyüme gelişim döneminde ortopedik yaklaşımlarla düzeltilse bile üst ve alt çene arasında orantısız büyümenin devam ettiği, üst çenenin yetersiz büyümesine karşın alt çenede aşırı büyümeye bağlı olarak sınıf 3 maloklüzyonun tekrar görülebildiğini bildiren çalışmalar mevcuttur. ${ }^{16,20,21}$ Bu görüşün aksine Sınıf 3 maloklüzyonun düzeltilmesinden sonra uygun oklüzal ilişkiler sağlandığında üst çenenin alt çenedeki büyümeye ayak uydurduğunu ve bu uyumun büyüme döneminin sonuna kadar devam ederek Sınıf 1 ilişkiyi koruduğu da bildirilmektedir. ${ }^{22,23}$ Bu nedenle bu çalışmada Sınıf 3 maloklüzyonların büyüme ve gelişim döneminde hızlı üst çene genişletmesi ve ortopedik yüz maskesi yöntemi ile düzeltilmesinin ve sonrasında uygulanan sabit ortodontik tedavinin etkile- rinin ve kalıcılığının değerlendirilmesi amaçlanmıştır.

Çalışmamızda ortopedik yüz maskesi ile birlikte hızIı üst çene genişletme apareyi kullanılmıştır. Sınıf 3 maloklüzyonların oluşumunda etkili olan üst çene gelişim yetersizliği uzayın her üç yönünde de görülebildiğinden üst çenenin büyümesinin sadece ileri yönde değil, diğer yönlerde de teşvik edilmesi gerekebilmektedir. Bununla birlikte yüz maskesi ile birlikte yapılan hızlı üst çene genişletmesinin üst çenenin çevresindeki 9 kemikle yaptığı sütüral bağlantıyı bozarak bu sütürlerde hücresel aktivasyonu arttırdığı, üst çenenin aşağı ve öne hareketini kolaylaştırdığını bildiren çeşitli çalışmalar mevcuttur. ${ }^{10,11,24}$

Yüz maskesi ile yapılan çalışmalar incelendiğinde tedavi etkileri ile büyümenin etkilerini birbirinden ayırt etmek için tedavi edilmemiş bireylerden oluşan kontrol gruplarının kullanıldığı görülmektedir. ${ }^{14,16,21}$ Ancak iskeletsel Sınıf 3 maloklüzyona sahip bireylerin baş ve yüz bölgelerindeki büyümelerini yönlendirmek için büyüme ve gelişim dönemi içerisinde tedavi edilmeleri gerektiğinden ve bu tip maloklüzyonları uzun süre bekletmek etik olmayacağından bu çalışmada kontrol grubu kullanılmamıştır.

Çalışmamızda hızlı üst çene genişletme ve yüz maskesi uygulaması sonrası SNA açısında $1.5^{\circ}$ anlamlı artış meydana gelmiş ve bu artış sabit tedavi süresince korunarak toplam tedavi sonunda anlamlı düzeyde stabil kalmıştır. Co-A uzunluğunda ise hızlı üst çene genişletilmesi ve yüz maskesi uygulaması sonrasında $3 \mathrm{~mm}$ ve toplam sürede 5.5 mm'lik artış elde edilmiştir. Bu bulgular hızlı üst çene genişletilmesi ve yüz maskesi uygulamasının üst çenede olumlu değişiklikler meydana getirdiği ve bu değişimlerin sabit tedavi süresince korunduğunu göstermektedir. Çalışmamızdan elde ettiğimiz bulgulara benzer şekilde literatürde hızlı üst çene genişletmesi ve yüz maskesi uygulaması sonrası üst çenenin ileri yönde hareket ettiğini ve uzun dönemde bu hareketin stabil kaldığını bildiren çalışmalar mevcuttur. ${ }^{7,14,18,19}$ Ngan ve ark. ${ }^{19}$ hızlı üst çene genişletmesi ve yüz maskesi uygulamasının uzun dönem sonuçlarını inceledikleri çalışmalarında, tedavi sonunda üst çenede anlamlı düzeyde ileri yönde hareket meydana geldiğini, tedaviden sonraki 2 ve 4 yıllık dönemde de tedavi grubunda üst çenenin kontrol grubuna göre daha fazla miktarda ileri ve aşağı yönde hareket ettiğini bildirmişlerdir. Westwood ve ark.14 benzer protokollerle yürüttükleri çalışmalarında, üst çene protraksiyonu sonrası SNA açısında $1.6^{\circ}$, CoA mesafesinde ise $2.4 \mathrm{~mm}$ anlamlı artış ile birlikte üst çenede kabul edilebilir düzeyde ileri yön büyüme elde ettiklerini, sabit ortodontik tedavi süresince ise SNA açısının değişmeden stabil kaldığı$\mathrm{nı}$; CoA mesafesinin ise Sınıf 3 kontrol grubu ile benzer artış gösterdiğini bildirmişlerdir. Araştırmacılar, 5.5 yıllık sabit ortodontik tedavi ve takip süresinde Sınıf 3 yapıda belirgin bir nüks gözlenmediğini bildirmişlerdir. Benzer şekilde Pangrazio-Kulbersh ve ark. ${ }^{15}$ yüz maskesi döneminde SNA açısının ve CoA mesafesinin anlamlı düzeyde arttığını, sabit ortodontik tedavi döneminde SNA açısının değişmeden stabil kaldığını ve CoA mesafe- 
sinin Sınıf 3 kontrol grubuna benzer artış gösterdiğini bildirmişlerdir. Chen ve ark. ${ }^{16}$ yüz maskesi uygulaması sonucunda üst çenenin ileri yönde büyüdüğünü, sabit ortodontik tedavinin üst çenenin ileri yön gelişimine herhangi bir katkı sağlamadığını, bu nedenle uzun dönem takiplerde dentoalveolar yapılarda meydana gelen düzelmenin kalıcı olmayabileceğini ve Sınıf 3 maloklüzyonun tekrar oluşabileceğini bildirmişlerdir.

Çalışmamızda hızlı üst çene genişletmesi ve yüz maskesi uygulaması sonrası, SNB açısında azalma ve yüz maskesi uygulaması sonrası ve toplam tedavi süresi sonrası, SN/GoGn açısında anlamlı artışlarla birlikte alt çenede aşağı ve geriye doğru rotasyon meydana gelmiştir. Alt yüz yüksekliğinde yüz maskesi uygulaması sonrası ve toplam tedavi süresi sonrası görülen artış da bu bulguları desteklemektedir. Yüz maskesi ile yapılan benzer çalışmalarda, alt çenedeki bu değişimin yüz maskesinin çene ucuna arka yönde uyguladığı kuvvet, diş destekli ankraj elemanlarının neden olduğu molar ekstrüzyonu ve üst çene düzleminde öne ve yukarı yönde meydana gelen rotasyon ile ilişkili olduğu bildirilmiştir. ${ }^{7,13,25}$ Ek olarak sabit ortodontik tedavi esnasında uygulanan mekaniklerin dişlerde ekstrüzyona neden olabileceği ve bu değişimlerin de alt çenenin aşağı ve geriye rotasyonuna yol açabileceği göz önünde bulundurulmalıdır. Çalışmamızda alt çenenin efektif uzunluğunun (Co-Gn) yüz maskesi uygulanması döneminde daha az olmakla birlikte tüm zamanlarda anlamlı artış gösterdiği gözlemlenmiştir. Bu sonuçlar hızlı üst çene genişletmesi ve yüz maskesi uygulamasının ve sabit ortodontik mekaniklerin alt çenenin büyüme yönünü değiştirirken boyutsal büyümesini engelleyemediğini göstermektedir. Literatürde alt çenenin efektif uzunluğunun büyümesinin yüz maskesi ile engellendiğisi,18 veya değiştirilemediğini ${ }^{12,26}$ bildiren çalışmalar mevcut olup yüz maskesi uygulaması sonlandırılıktan sonra alt çenenin büyümeye devam ettiği ve Sınıf 3 yapının nüksünde etkili olduğu bildirilmektedir. ${ }^{18}$

ANB açısında ve Wits değerinde yüz maskesi uygulaması sonu ve toplam tedavi süresinde elde edilen istatistiksel olarak anlamlı artışlar, iskeletsel Sınıf 3 yapıda özellikle yüz maskesi uygulamasına bağlı anlamlı düzelmeler meydana geldiğini ve sabit tedavi sonuna kadar çeneler arası ilişkinin korunduğunu göstermektedir. Çeneler arası ilişkide elde edilen bu düzelme üst çenenin ileri yön hareketi ve alt çenenin aşağı ve geriye rotasyonunun sonucunda elde edilmiş olup sabit ortodontik tedavi sonuna kadar yapılan takip döneminde herhangi bir nüks gözlemlenmemiştir. Bu görüşün aksine bazı yazarlar çeneler arası ilişkide görülen iyileşmenin daha çok alt çenedeki geriye doğru rotasyon ve dişsel değişikliklere bağlı olduğunu, üst çenenin ileri yön hareketinin katkısının çok az olduğunu bu nedenle uzun dönemde nüksün kaçınılmaz olduğunu bildirmektedirler. ${ }^{14,21,27}$ Kaygısız ve Yüksel ${ }^{18}$ ANB açısının uygulama döneminde arttığını ancak uzun dönem takip döneminde azalma gözlemlendiğini ve bireysel büyüme modeline bağlı olarak nüks görülebildiğini bildirmişlerdir.
Literatürde, diş destekli ağız içi ankraj ünitesinden destek alınarak uygulanan yüz maskesi sonrası üst kesicilerde protrüzyon, yüz maskesinin çenelik kısmının alt kesicilere kuvvet uygulaması nedeniyle de alt keserlerde dikleşme meydana geldiği pek çok araştırmada belirtilmiştir. ${ }^{2,12,13,16,19,21}$ Ancak bu çalışmada önceki literatür bilgilerinin aksine hızlı üst çene genişletme apareyinden destek alınarak uygulanan yüz maskesinin alt ve üst kesici konumunda anlamlı bir değişikliğe neden olmadığı gözlenmiştir. Bununla birlikte üst kesiciler sabit ortodontik tedavi sonrasında anlamlı düzeyde protrüze olmuşlardır. Bu değişimin sabit ortodontik tedavi sırasında uygulanan mekaniklerin (sınıf 3 elastikler, yer kazanmak için keser protrüzyonu) bir sonucu olduğu düşünülmektedir.

Yüz maskesi uygulaması sonrasında ön çapraz kapanışın düzeltilerek pozitif overjet değeri elde etmek ve bu değeri korumak tedavinin başarısını ve uzun dönem stabiliteyi değerlendirmede kullanılan önemli bir klinik göstergedir. Yüz maskesi uygulaması sonrası overjette üst çenenin öne hareketi, alt çenenin aşağı ve geriye hareketi, üst keserlerin protrüzyonu ve alt keserlerin dikleşmesi ile düzelme sağlandığı bildirilmektedir. ${ }^{11,28-30}$ Çalışmamızda da benzer şekilde yüz maskesi uygulaması sonucunda $3.5 \mathrm{~mm}$ anlamlı overjet artışı ile birlikte ön çapraz kapanışın düzeldiği ve sabit tedavi sonuna kadar değişmeden kaldığı gözlemlenmiştir. Bu değişimin çoğunlukla üst çenenin öne hareketi ve alt çenenin aşağı ve geriye hareketi ile elde edildiği düşünülmektedir. Yapılan uzun dönemli takip çalışmaları incelendiğinde, alt çenenin ileri yön büyümesinin devam etmesine bağlı overjette azalma meydana gelebileceği bildirilmektedir. ${ }^{14,18,19}$ Yüz maskesi ile tedavi edilmiş vakalarda uzun dönem takip sonrası overjetin hala pozitif değerlerde kalma oranını Westwood ve ark. ${ }^{14} \% 76$, Ngan ve ark. ${ }^{19}$ ise \%75 olarak bildirmişlerdir.

Çalışmamızda üst dudak ile ile Steiner'in S düzlemi arasındaki mesafede yüz maskesi uygulaması sonrasında anlamlı artış ile birlikte yumuşak doku profilinin iyileştiği gözlemlenmiştir. Üst dudağın ileri yön konumunda görülen bu artış, üst çenenin ileri yön hareketinin bir sonucudur. Daha önceki yüz maskesi çalışmaları üst dudak mesafesindeki artışın üst çenedeki ileri yön hareketinin yanı sıra üst keserlerde görülen protrüzyon ile ilişkili olduğunu bildirmektedirler. ${ }^{31}$

Bu çalışmadan elde edilen bulgular büyüme ve gelişim döneminde iskeletsel Sınıf 3 maloklüzyonun düzeltilmesinden sonra uygun oklüzal ilişkiler sağlandığında üst çenenin alt çene büyümesine ayak uydurduğunu ve bu uyumun Sınıf 1 ilişkiyi koruduğunu göstermektedir. $\mathrm{Bu}$ nedenle çalışmanın hipotezi geçerliliğini korumuştur. Ancak çalışmamızın bireylerin sabit ortodontik tedavinin hemen sonrasında değerlendirilmesi, bireylerin büyüme ve gelişimini büyük bir kısmını tamamlasa da hala büyüme potansiyellerinin varlığı ve sınırlı sayıda hasta grubu üzerinde yapılması gibi birtakım kısıtılıkları bulunmaktadır. Ayrıca çalışmanın retrospektif olması nedeniyle materyali tedavileri başarılı bir şekilde tamamlanıp arşivlenmiş hastalardan oluşmakta bu ne- 
denle tedavisi başarısızlıkla sonuçlanmış bireyler konusunda yetersiz bilgi sağlamaktadır. Bu nedenle daha fazla birey sayısı ile büyüme ve gelişim dönemlerinin sonuna kadar takip edilen randomize prospektif çalışmalar planlanması iskeletsel Sınıf 3 maloklüzyonların tedavilerinde görülebilecek olası nüksler için daha değerli bilgi sağlayacaktır.

\section{Sonuç}

İskeletsel Sınıf 3 maloklüzyonların büyüme ve gelişim dönemi içindeki tedavilerinde hızlı üst çene genişletmesi ve yüz maskesinin birlikte uygulanmasının etkili bir yöntem olduğu, sabit ortodontik tedavi sonuna kadar yapılan takip döneminde Sınıf 3 yapıya geri dönüş saptanmadığı gözlenmiştir.

\section{TEŞEKKÜR VE ANMA}

Bu araştırma, 13-17 Ekim 2018 tarihleri arasında İzmir, Türkiye'de yapılmış olan 16. Uluslararası Türk Ortodonti Derneği Kongresinde poster bildirisi olarak sunulmuştur.

\section{KAYNAKLAR}

1. Graber TM, Vanarsdall RL. Orthodontics: Current Principles and Techniques. 3rd ed. St Louis: Mosby; 2000.

2. Ngan P, Hagg U, Yiu C, Merwin D, Wei SH. Treatment response to maxillary expansion and protraction. Eur J Orthod 1996;18:151-68.

3. Franchi L, Baccetti T, Tollaro I. Predictive variables for the outcome of early functional treatment of Class III malocclusion. Am J Orthod Dentofacial Orthop 1997;112:80-6.

4. Woon SC, Thiruvenkatachari B. Early orthodontic treatment for Class III malocclusion: A systematic review and meta-analysis. Am J Orthod Dentofacial Orthop 2017;151:28-52.

5. Dietrich UC. Morphological variability of skeletal Class 3 relationships as revealed by cephalometric analysis. Rep Congr Eur Orthod Soc 1970:131-43.

6. Ellis E 3rd, McNamara JA Jr, Lawrence TM. Components of adult Class II open-bite malocclusion. J Oral Maxillofac Surg 1985;43:92105.

7. Gallagher RW, Miranda F, Buschang PH. Maxillary protraction: treatment and posttreatment effects. Am J Orthod Dentofacial Orthop 1998;113:612-9.

8. Turley PK. Managing the developing Class III malocclusion with palatal expansion and facemask therapy. Am J Orthod Dentofacial Orthop 2002;122:349-52

9. Foersch M, Jacobs C, Wriedt S, Hechtner M, Wehrbein H. Effectiveness of maxillary protraction using facemask with or without maxillary expansion: a systematic review and meta-analysis. Clin Oral Investig 2015;19:1181-92.

10. Vaughn GA, Mason B, Moon HB, Turley PK. The effects of maxillary protraction therapy with or without rapid palatal expansion: a prospective, randomized clinical trial. Am J Orthod Dentofacial Orthop 2005;128:299-309.

11. Baccetti T, McGill JS, Franchi L, McNamara JA Jr, Tollaro I. Skeletal effects of early treatment of Class III malocclusion with maxillary expansion and face-mask therapy. Am J Orthod Dentofacial Orthop 1998;113:333-43.

12. Tortop T, Keykubat A, Yuksel S. Facemask therapy with and without expansion. Am J Orthod Dentofacial Orthop 2007;132:467-74.

13. Kapust AJ, Sinclair PM, Turley PK. Cephalometric effects of face mask/expansion therapy in Class III children: a comparison of three age groups. Am J Orthod Dentofacial Orthop 1998;113:204-12.
14. Westwood PV, McNamara JA Jr, Baccetti T, Franchi L, Sarver DM. Long-term effects of Class III treatment with rapid maxillary expansion and facemask therapy followed by fixed appliances. Am J Orthod Dentofacial Orthop 2003;123:306-20.

15. Pangrazio-Kulbersh V, Berger JL, Janisse FN, Bayirli B. Long-term stability of Class III treatment: rapid palatal expansion and protraction facemask vs LeFort I maxillary advancement osteotomy. Am J Orthod Dentofacial Orthop 2007;131:7.e9-19.

16. Chen L, Chen R, Yang Y, Ji G, Shen G. The effects of maxillary protraction and its long-term stability--a clinical trial in Chinese adolescents. Eur J Orthod 2012;34:88-95.

17. Pavoni C, Gazzani F, Franchi L, Loberto S, Lione R, Cozza P. Soft tissue facial profile in Class III malocclusion: long-term post-pubertal effects produced by the Face Mask Protocol. Eur J Orthod 2019;21;41:531-36.

18. Kaygısız E, Yüksel S. Yüz maskesi uygulamasının uzun dönem sonuçlarının değerlendirilmesi. Acta Odontol Turc 2014;31:127-33.

19. Ngan PW, Hagg U, Yiu C, Wei SH. Treatment response and longterm dentofacial adaptations to maxillary expansion and protraction. Semin Orthod 1997;3:255-64.

20. Baik HS. Limitations in orthopedic and camouflage treatment for Class III malocclusion. Semin Orthod 2007;13:158-74.

21. Macdonald KE, Kapust AJ, Turley PK. Cephalometric changes after the correction of class III malocclusion with maxillary expansion/ facemask therapy. Am J Orthod Dentofacial Orthop 1999;116:13-24.

22. Anderson I, Rabie AB, Wong RW. Early treatment of pseudo-class III malocclusion: a 10-year follow-up study. J Clin Orthod 2009;43:6928.

23. Almeida RR, Alessio LE, Almeida-Pedrin RR, Almeida MR, Pinzan A, Vieira LS. Management of the Class III malocclusion treated with maxillary expansion, facemask therapy and corrective orthodontic. A 15-year follow-up. J Appl Oral Sci 2015;23:101-9.

24. Zhang W, Qu HC, Yu M, Zhang Y. The Effects of Maxillary Protraction with or without Rapid Maxillary Expansion and Age Factors in Treating Class III Malocclusion: A Meta-Analysis. PLoS One 2015;10:e0130096.

25. Ishii H, Morita S, Takeuchi $Y$, Nakamura S. Treatment effect of combined maxillary protraction and chincap appliance in severe skeletal Class III cases. Am J Orthod Dentofacial Orthop 1987;92:304-12.

26. Mermigos J, Full CA, Andreasen G. Protraction of the maxillofacial complex. Am J Orthod Dentofacial Orthop 1990;98:47-55.

27. Lertpitayakun P, Miyujima K, Kanomi R, Sinha PK. Cephalometric changes after long-termearly treatment with face mask and maxillary intraoral appliance therapy. Semin Orthod 2001;7:169-79.

28. Nartallo-Turley PE, Turley PK. Cephalometric effects of combined palatal expansion and facemask therapy on Class III malocclusion. Angle Orthod 1998;68:217-24.

29. Cha BK, Choi DS, Ngan P, Jost-Brinkmann PG, Kim SM, Jang IS. Maxillary protraction with miniplates providing skeletal anchorage in a growing Class III patient. Am J Orthod Dentofacial Orthop 2011;139:99112.

30. Ngan P, Yiu C, Hu A, Hagg U, Wei SH, Gunel E. Cephalometric and occlusal changes following maxillary expansion and protraction. Eur $J$ Orthod 1998;20:237-54.

31. Kilicoglu H, Kirlic Y. Profile changes in patients with class III malocclusions after Delaire mask therapy. Am J Orthod Dentofacial Orthop 1998;113:453-62.-9. 


\section{Effects of rapid maxillary expansion and facemask therapy followed by fixed orthodontic treatment in Class 3 malocclusions}

\begin{abstract}
OBJECTIVE: The aim was to evaluate the effects of rapid palatal expansion and facemask therapy followed by fixed orthodontic treatment in Class 3 malocclusions with maxillary hypoplasia.

MATERIALS AND METHOD: The study was constituted from archive materials of 20 patients ( 11 females, 9 males, median of chronological age: $\mathbf{1 1 . 2 9}$ years) who were treated with rapid palatal expansion and facemask therapy followed by fixed orthodontic treatment. Lateral cephalometric radiographs of the patients were evaluated before treatment (T0), after rapid palatal expansion and facemask therapy (T1), and after fixed orthodontic treatment (T2). Friedman and post-hoc Wilcoxon tests with Bonferroni correction were used, and $p<0.05$ was considered as significant.
\end{abstract}

RESULTS: The duration of rapid palatal expansion and facemask therapy was 13 months (T1-T0), fixed orthodontic treatment was 2 years and 1 month (T2-T1), and total treatment was 3 years and 2 months (T2-T0). The increase in SNA angle and Co-A dimension at T1-TO $(p<0.001)$ and T2T0 (SNA: $p<0.001$, Co-A: $p<0.01$ ) periods were statistically significant. SNB angle showed a significant decrease at T1-T0 $(p<0.01)$ while Co-Gn dimension increased significantly at all periods (T1-T0 and T2-T1: $p<0.05$, T2-T0: $\mathrm{p}<0.001)$. SN/GoGn angle also increased significantly at T1-T0 $(p<0.05)$ and T2-T0 $(p<0.001)$ periods. A significant increase was obtained in the ANB angle at T1-T0 and T2TO periods $(p<0.001)$.

ConCLUSION: In the treatment of skeletal Class 3 malocclusions, rapid palatal expansion and facemask therapy is an effective method. Stable treatment outcomes were obtained after fixed orthodontic treatment with a harmonious maxillo-mandibular growth.

KEYwords: Angle Class III; malocclusion; orthodontic appliances 